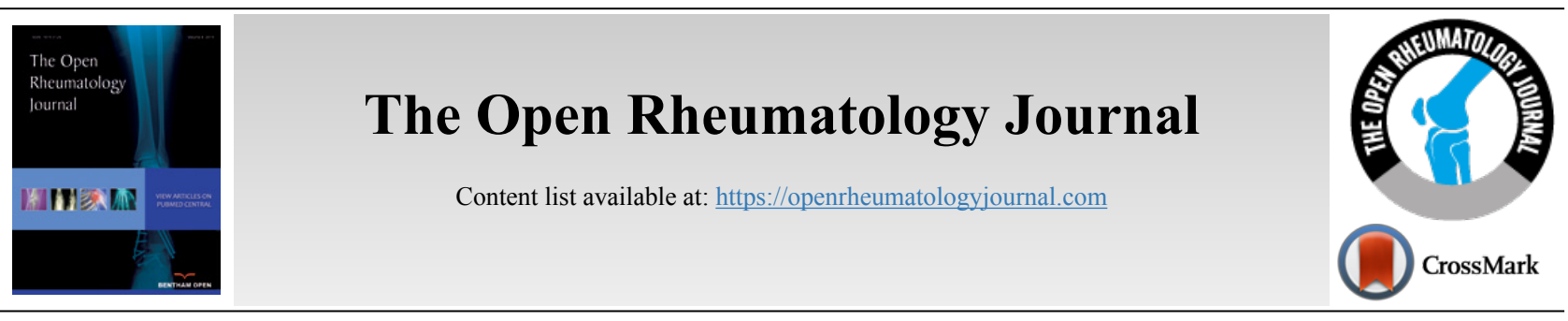

RESEARCH ARTICLE

\title{
Baseline Characteristics of Patients with Ankylosing Spondylitis and Psoriatic Arthritis Treated with Secukinumab in the Real-World Setting: AQUILA, a Non-Interventional Study
}

\author{
Uta Kiltz $^{1}$, Carolin Legeler ${ }^{2,}$, Monika Maier-Peuschel ${ }^{2}$, Christian Mann $^{2}$ and Hans-Peter Tony ${ }^{3}$ \\ ${ }^{I}$ Rheumazentrum Ruhrgebiet and Ruhr-University Bochum, Herne, Germany \\ ${ }^{2}$ Novartis Pharma GmbH, Nürnberg, Germany \\ ${ }^{3}$ Rheumatology/Clinical Immunology, University Hospital of Wuerzburg, Wuerzburg, Germany
}

\begin{abstract}
:
Objective:

AQUILA is an ongoing, multicenter, prospective, Non-Interventional Study (NIS) with secukinumab, designed to evaluate real-world evidence for different aspects of treatment in patients with Ankylosing Spondylitis (AS) and psoriatic arthritis (PsA) in Germany. Here we report the study design and baseline characteristics including comorbidities and prior medication of patients as well as insights into medical care in Germany.

Methods:

Patients (age $\geq 18$ years) with active AS or PsA, who were under secukinumab treatment or just about initiating secukinumab therapy based on medical therapeutic need, are enrolled. Each patient is observed for 52 weeks.

Results:

A total of 572 patients (AS, $n=187$; PsA, $n=385$ ) have been recruited in this ongoing study. Mean age, weight, and BMI were similar between the subgroups. About $66.4 \%$ of patients had previously received biologics other than secukinumab. Depression was the most common comorbidity (AS, 9.1\%; PsA, 15.6\%). Plaque psoriasis was also frequently reported (AS, 9.6\%; PsA, 62.3\%).

\section{Conclusion:}

The Non-Interventional Study (NIS) baseline characteristics indicate that the demographics were similar to populations of previous secukinumab trials of AS and PsA patients except to comorbidities and exposure to biologics. A majority of the patients who received secukinumab in this setting had previously received biologics. Comorbidities relating to obesity and cardiovascular disease were particularly evident in PsA patients whereas the elevated depression prevalence was equally distributed.
\end{abstract}

Keywords: Ankylosing spondylitis, Psoriatic arthritis, Non-interventional study, Secukinumab, Comorbidity, AQUILA.

\section{Article History} Received: February 15, 2019

Revised: March 22, 2019 Accepted: April 10, 2019

\section{INTRODUCTION}

Ankylosing Spondylitis (AS) and psoriatic arthritis (PsA) belong to the spondyloarthritis (SpA) class of chronic inflammatory progressive diseases characterized by pain, stiffness, fatigue, disability, and reduced health-related Quality of Life (QoL) [1,2] AS and PsA might be associated with radiographically detectable structural changes [2 - 4]. The

\footnotetext{
* Address correspondence to this author at the Clinical Research, Immunology, Hepatology \& Dermatology, Novartis Pharma GmbH, Roonstrasse 25, D-90429 Nuernberg, Germany; Tel: 0911273 13942; Fax: 091127317942 E-mail: carolin.legeler@novartis.com
}

global prevalence of SpA ranges from $1 \%-1.4 \%[5,6]$. In Germany, AS carries a prevalence of $0.2 \%-1.4 \%$, and PsA is slightly less common at $0.1 \%-0.2 \%[2,7]$. The standard therapy for AS and PsA includes first-line treatment with NonSteroidal Anti-Inflammatory Drugs (NSAIDs). As second-line treatment, app-roved biologics are prescribed for AS patients and Disease-Modifying Antirheumatic Drugs (DMARDs) for PsA patients [8]. If an inadequate response or intolerance is reported to conventional treatment options, current practice guidelines recommend initiating biologics, usually an antitumor necrosis factor (TNF) therapy in both AS and PsA. AntiTNF therapies effectively relieve symptoms of patients with 
AS $[7,8]$ and PsA $[9,10]$, but patients may have an inadequate response or do not tolerate these agents, necessitating further treatment options. Thus, there remains an unmet need for effective thera-pies with a different mechanism of action.

The interleukin (IL)-17 is a key cytokine involved in the pathogenesis of SpA [11, 12]. Secukinumab, a fully human monoclonal antibody that directly inhibits IL-17A, has been shown to have significant efficacy in the treatment of moderate to severe psoriasis, with PsA and AS demonstrating a rapid onset of action and sustained responses with a favorable safety profile [13 - 15]. Secukinumab has been approved in Germany for the treatment of active AS and PsA $[16,17]$. However, data from Randomized Clinical Trials (RCTs) do not completely represent secukinumab therapy in a real-world setting; as clinical studies are highly regulated and do not necessarily represent everyday practice. Further, RCTs have a generally smaller, well-defined study population while real-world studies complement RCTs and further assess the effectiveness/safety of medications in a more realistic diverse clinical setting. Therefore, the Non-Interventional Study (NIS) AQUILA was designed to evaluate real-life data with a focus on effectiveness, safety, and tolerability of secukinumab in patients with active AS or PsA in daily practice in Germany.

\section{METHODS}

Here we report the baseline characteristics including, disease activity, comorbidities and prior medication of AS and PsA patients who are entering the NIS AQUILA as well as insights into medical care in Germany.

\subsection{Study Design and Patients}

AQUILA is an ongoing NIS, which will provide real-world effectiveness, safety, and the adherence rate of secukinumab from patients with active AS or active PsA in Germany at Week 52 (Fig. 1). The AQUILA study is being carried out between February 2016 and February 2020 across 250 centers in Germany, with 2,000 patients targeted for inclusion. The study includes patients $\geq 18$ years old with high disease activity of AS or PsA (per physician's diagnosis) who are receiving secukinumab treatment based on therapeutic need and based on locally approved prescribing information [16]. An observation period of 52 weeks is planned for each patient. Suitable patients are enrolled into the NIS nonselectively after information about study procedures and agreement by the patient. Patients were allowed to enter the study if they are receiving or are about to receive secukinumab for the therapeutic indication AS or PsA. Treatment decision was made independently of participating in this trial. Patients were recruited by rheumatologists as well as orthopedists in an outpatient setting aiming at the achievement of a representative sample of SpA patients in Germany. The ethics committee (University of Würzburg, Germany; reference number 316/ 15_awb) advice was obtained and recommendations implemented. All patients gave informed consent.

\subsection{Outcomes}

The primary objective of this study is to determine the adherence rate (defined as the number of patients with adherence $>80 \%$ at 52 weeks compared to the number of patients at baseline) over 52 weeks in all patients who received secukinumab as a new or continued treatment in a real-life setting. Adherence itself at the given time point is expressed as the portion of patients taking secukinumab in accordance with the label (target dose and target interval) until the given time point.

Secondary endpoints include the assessment of disease activity as measured by Physician's Global Assessment (PhGA) [18], Bath Ankylosing Spondylitis Disease Activity Index (BASDAI) [19], Psoriasis Area and Severity Index [20], American College of Rheumatology count for tender and swollen joints [21], and C-Reactive Protein (CRP). The change from baseline in the following patient-reported outcomes will also be assessed: the Assessment of SpondyloArthritis international Society (ASAS) Health Index (HI) in AS patients [22], 12-item Psoriasis Arthritis Impact of Disease (PsAID-12) in PsA patients [23], and Beck Depression Inventory [24].

Comorbidities and extra-articular manifestations must be diagnosed by a physician. In scope are coronary heart disease, stroke, heart failure, plaque psoriasis, uveitis and dep-ression. Severity of psoriasis (mild/moderate/severe) at base-line is based on the physician's discretion/ based on clinical personnel opinion (not based on cut-offs), which represents real-world clinical practices. Questions about symptom duration and time since diagnosis were patient-reported.

\subsection{Sample Size and Analysis}

Sample size considerations are based on formal statistical principles; however, in NIS, they can only provide general guidance regarding the control of the alpha error and statistical power. We calculated sample size based on the incidence of the disease, expected patient recruitment within the study duration, and the relationship between the sample size and overall population. During the ongoing secukinumab clinical study program, a discontinuation rate of approximately $12 \%$ has been reported during the first year $[13,14,25]$. Based on this estimation, the AQUILA study will target a sample of 2,000 patients at potentially 250 study centers. Assuming an adherence rate of $88 \%, 1,800$ patients will remain on therapy at the end of the 52-week study period. Using a double-sided confidence interval of $95 \%$, this sample size will be sufficient to estimate the adherence rate with a precision of $3.0 \%$ and $1.5 \%$ for the upper and lower intervals, respectively. All the results will be compared to baseline and will be analyzed separately in AS and PsA patients with subgroup analyses for TNF-naïve and TNF-inadequate responder patients.

Descriptive statistics are used for all assessed criteria including, but not limited to, effectiveness, QoL, compliance, concomitant treatments, and comorbidities. Descriptive data are presented as absolute frequencies and percentages when 


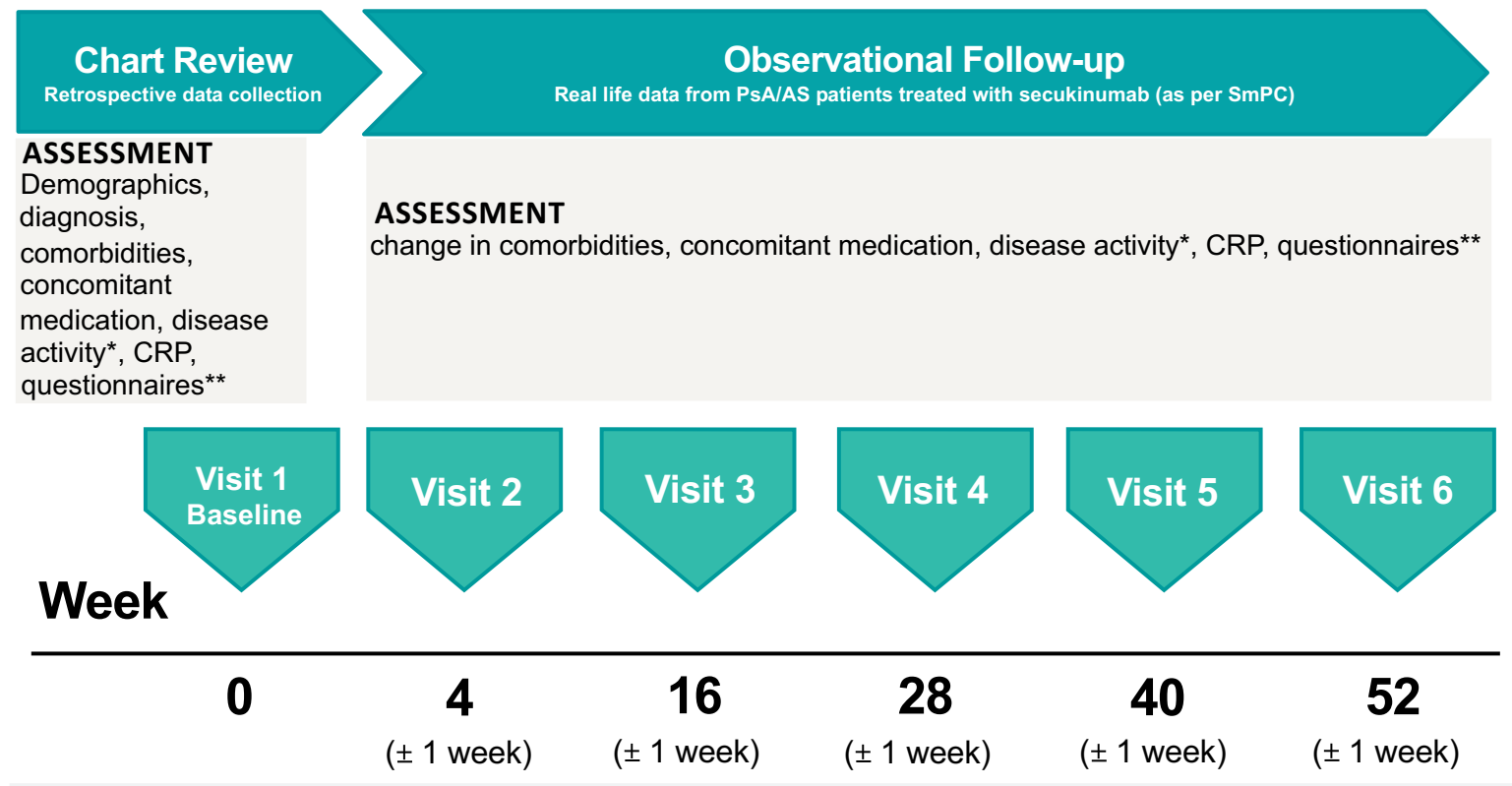

Fig. (1). Study design of AQUILA.

Patient's Global Assessment, Physician's Global Assessment; Bath Ankylosing Spondylitis Disease Activity Index; Joint Count, Psoriasis Area and Severity Index and Leeds Enthesitis Index

**Becks Depression Inventory-II; Assessment of SpondyloArthritis International Society Health Index; Psoriasis Arthritis Impact of Disease and Medical Outcomes Study 12-item Sleep Scale AS: Ankylosing spondylitis; PsA: Psoriatic arthritis, SmPC, Summary of Product Characteristics; CRP, C-Reactive Protein

referring to qualitative variables. Continuous variables are expressed as the mean \pm Standard Deviation (SD) or as the median with interquartile range (IQR, range $25-75 \%$ ) where appropriate. The Mann-Whitney $U$ test was used to compare data between subgroups at single time points; a value of $<0.05$ was considered statistically significant.

\section{RESULTS}

\subsection{General Demographic Characteristics}

Of 720 consented patients, baseline characteristics of 572 patients with active AS $(n=187)$ and PsA $(n=385)$ were available and were thus included in this interim analysis (full analysis set, data cut-off 01.02.2017). Table 1 shows the key demographic characteristics of patients with AS and PsA included in the study. In general, mean age, weight, and Body Mass Index (BMI) were similar between the AS and PsA groups. In the AS population, the majority of the patients were male $(64.2 \%)$, whereas in the PsA population, the majority were female $(58.2 \%)$. Mean BMI $\left(\mathrm{kg} / \mathrm{m}^{2}\right.$, mean $\left.\pm \mathrm{SD}\right)$ was above the normal weight BMI category of $<25$ in both groups (AS, 27.6 \pm 5.0 and PsA, 29.2 \pm 6.1 ) [26]. According to standard BMI categories, $65.9 \%$ of AS and $73.9 \%$ of PsA patients are overweight (BMI 25.0-29.99), and $29.7 \%$ of AS and $39.4 \%$ of PsA patients are obese $(\mathrm{BMI} \geq 30)$. The smoker status of AS and PsA patients was comparatively similar (smoker $33.9 \%$ vs $26.5 \%$, ex-smoker $16.7 \%$ vs. $17.1 \%$ and non-smoker $39.8 \%$ vs. $48.8 \%$ ), whereby $85 \%$ of the smoking AS patients are smoking for at least 10 years or longer $(91.2 \%$ of PsA patients respectively). In the current study, $22.5 \%$ of the PsA patients lacked a confirmed diagnosis for 10 years or more after symptom onset; only $43.2 \%$ had a confirmed diagnosis within 2 years. In the AS population, $24.8 \%$ of patients received a diagnosis after 10 years or more of experiencing symptoms, and only $34.5 \%$ had a confirmed diagnosis within 2 years (Table 1). Only a small proportion (23.8\%) of AS and PsA patients were diagnosed within one year of patient-reported symptom onset.

\subsection{Disease Characteristics at Baseline in Patients with AS}

AS patients showed high disease activity, with a mean (SD) BASDAI of 5.5 (1.9). CRP was elevated, with a median (IQR) of $7.6 \mathrm{mg} / \mathrm{L}(3.0-22.0 \mathrm{mg} / \mathrm{L})$. About half of the patients (50.3\%) had a CRP level above the normal value of $5.0 \mathrm{mg} / \mathrm{L}$. At baseline, patients reported reduced global functioning as a surrogate for QoL, with an impaired mean ASAS-HI score (SD) of 8.4 (3.7). Plaque psoriasis was common, occurring in 9.6\% of patients with AS and history of uveitis was reported in a small proportion of patients $(4.8 \%)$ (Table 2 ).

Among the reported comorbidities, depression was the most common (9.1\%) in patients with AS. As shown in Table 2, a relatively small proportion of patients with AS had severe coronary heart disease, stroke, or heart failure.

\subsection{Disease Characteristics at Baseline in Patients with PsA}

Patients with PsA had a high disease activity with a mean (SD) high number of tender $\{7.9(8.1)\}$ and swollen joints $\{4.1$ (5.5) $\}$. The median (IQR) CRP was $4.6 \mathrm{mg} / \mathrm{L}(2.2-11.8 \mathrm{mg} / \mathrm{L})$ with $38.4 \%$ of patients had CRP levels above the normal value of $5.0 \mathrm{mg} / \mathrm{L}$. Patients reported reduced QoL at baseline, as shown by a mean (SD) PsAID-12 score of 5.0 (2.2) (Table 2). Among the reported comorbidities, depression and coronary heart disease were the most common $(15.6 \%$ and $8.3 \%$, respectively). A total of $62.3 \%$ of PsA patients reported plaque psoriasis, and $12.5 \%$ had a severe form of psoriasis at baseline. 
Table 1. Demographic and baseline characteristics of patients.

\begin{tabular}{|c|c|c|c|c|}
\hline Characteristic $^{\dagger}$ & $\operatorname{AS}(N=187)$ & PsA $(\mathbf{N}=385)$ & P-value & Total $(\mathrm{N}=572)$ \\
\hline Age (years), mean (SD) & $46.6(12.2)$ & $53.0(11.1)$ & $<0.001^{\circ \circ}$ & $50.9(11.8)$ \\
\hline Male, n (\%) & $120(64.2)$ & $161(41.8)$ & $<0.001^{\circ}$ & $281(49.1)$ \\
\hline Weight (kg), mean (SD) & $83.5(15.9)$ & $85.7(19.0)$ & $0.315^{\circ 0}$ & $85.0(18.0)$ \\
\hline BMI $\left(\mathrm{kg} / \mathrm{m}^{2}\right)$, mean $(\mathrm{SD})$ & $27.6(5.0)$ & $29.2(6.1)$ & $0.007^{\circ 0}$ & $28.7(5.8)$ \\
\hline $\mathrm{BMI} \geq 25 \mathrm{~kg} / \mathrm{m}^{2}, \mathrm{n}(\%)$ & $122(65.9)$ & $278(73.9)$ & $0.059^{\circ}$ & $400(71.3)$ \\
\hline $\mathrm{BMI} \geq 30 \mathrm{~kg} / \mathrm{m}^{2}, \mathrm{n}(\%)$ & $55(29.7)$ & $148(39.4)$ & $0.031^{\circ}$ & $203(36.2)$ \\
\hline Non-smoker, n (\%) & $74(39.8)$ & $188(48.8)$ & NA & $262(45.9)$ \\
\hline Ex-smoker, n (\%) & $31(16.7)$ & $66(17.1)$ & NA & $97(17.0)$ \\
\hline Smoker, n (\%) & $63(33.9)$ & $102(26.5)$ & NA & $165(28.9)$ \\
\hline Smoking time $>10$ years, $\mathrm{n}(\%)$ & $51(85.0)$ & $83(91.2)$ & NA & $134(88.7)$ \\
\hline \multicolumn{5}{|c|}{ Duration between first symptoms and confirmed diagnosis**, $\mathrm{n}(\%)$} \\
\hline$<1$ year & $37(22.4)$ & $85(24.5)$ & $0.070^{\circ}$ & $122(23.8)$ \\
\hline 1 to $<2$ years & $20(12.1)$ & $65(18.7)$ & NA & $85(16.6)$ \\
\hline 2 to $<5$ years & $30(18.2)$ & $71(20.5)$ & NA & $101(19.7)$ \\
\hline 5 to $<10$ years & $37(22.4)$ & $48(13.8)$ & NA & $85(16.6)$ \\
\hline$\geq 10$ years & $41(24.8)$ & $78(22.5)$ & NA & $119(23.2)$ \\
\hline
\end{tabular}

"Assessment only, not the result itself

*Patient-reported (patient health record)

${ }^{\dagger}$ Missing values not included in \% calculations

AS, Ankylosing Spondylitis; BMI, Body Mass Index; HLA, Human Leukocyte Antigen; N, number of patients; NA, Not Applicable/Not Available; PsA, Psoriatic Arthritis; SD, Standard Deviation.

${ }^{\circ}$ Fisher's exact test, ${ }^{\circ}$ Wilcoxon test

Table 2. Baseline disease characteristics of patients with AS and PsA.

\begin{tabular}{|c|c|c|c|c|}
\hline Characteristics & AS $(N=187)$ & $\operatorname{PsA}(\mathbf{N}=385)$ & P-value & Total $(N=572)$ \\
\hline Disease activity at baseline, mean (SD) & - & - & - & - \\
\hline PhGA, score $0-10$ & $5.9(1.8)$ & $5.5(2.1)$ & $0.051^{\circ 00}$ & $5.6(2.0)$ \\
\hline BASDAI, score $0-10$ & $5.5(1.9)$ & NA & $0.384^{000}$ & $5.5(1.9)$ \\
\hline PASI, score & NA & $8.8(12.4)$ & NA & $8.8(12.4)$ \\
\hline Tender joints ( 68 joints) & NA & $7.9(8.1)$ & NA & $7.9(8.1)$ \\
\hline Swollen joints (66 joints) & NA & $4.1(5.5)$ & NA & $4.1(5.5)$ \\
\hline BDI-II, 0-63 & $12.7(9.2)$ & $11.5(9.2)$ & $0.127^{\circ 00}$ & $11.9(9.2)$ \\
\hline PsAID- $12,0-10$ & NA & $5.0(2.2)$ & NA & $5.0(2.2)$ \\
\hline ASAS-HI, 0-17 & $8.4(3.7)$ & NA & NA & $8.4(3.7)$ \\
\hline CRP (mg/L), median & 7.6 & 4.6 & $0.003^{\circ 00}$ & 5.5 \\
\hline CRP (mg/L) IQR (Q1-Q3) & $3.0-22.0$ & $2.2-11.8$ & NA & $2.4-13.5$ \\
\hline $\mathrm{CRP}>5.0 \mathrm{mg} / \mathrm{L}, \mathrm{n}(\%)$ & $94(50.3)$ & $148(38.4)$ & $0.004^{\circ}$ & $242(42.3)$ \\
\hline \multicolumn{5}{|c|}{ Comorbidities at baseline, $n(\%)$} \\
\hline Coronary heart disease & $5(2.7)$ & $32(8.3)$ & $0.065^{\circ \circ}$ & $37(6.5)$ \\
\hline Stroke & 0 & $8(2.1)$ & $0.134^{\circ \circ}$ & $8(1.4)$ \\
\hline Heart failure & $1(0.5)$ & $12(3.1)$ & $0.202^{\circ \circ}$ & $13(2.3)$ \\
\hline \multicolumn{5}{|c|}{ Plaque psoriasis $^{\dagger}$} \\
\hline Mild & $11(5.9)$ & $81(21.1)$ & NA & $92(16.1)$ \\
\hline Moderate & $6(3.2)$ & $111(28.9)$ & NA & $117(20.5)$ \\
\hline Severe & $1(0.5)$ & $48(12.5)$ & NA & $49(8.6)$ \\
\hline Uveitis & $9(4.8)$ & $3(0.8)$ & $0.005^{\circ \circ}$ & $12(2.1)$ \\
\hline Depression* & $17(9.1)$ & $60(15.6)$ & $0.021^{\circ \circ}$ & $77(13.5)$ \\
\hline
\end{tabular}

*Only in case of diagnosis by physician/reported in patient health record.

${ }^{\dagger}$ Missing values not included in the \% calculation for PsA subgroup.

ACR, American College of Rheumatology; AS, ankylosing spondylitis; ASAS-HI, Assessment of SpondyloArthritis international Society Health Index; BASDAI, Bath Ankylosing Spondylitis Disease Activity Index; BDI-II, Beck Depression Inventory; CHD, Coronary heart disease; CRP, C-Reactive Protein; IQR, interquartile range; N, number of patients; NA, Not Applicable/Not Available; PASI, Psoriasis Area and Severity Index; PhGA, Physician's Global Assessment; PsA, psoriatic arthritis; PsAID-12, Psoriasis Arthritis Impact of Disease (12-item); SD, standard deviation.

${ }^{\circ}$ Fisher's exact test, ${ }^{\circ} \mathrm{Chi}$-square test, ${ }^{\circ 0 \circ} \mathrm{Wilcoxon}$ test 
The assessed comorbidities were much higher in PsA patients than in the AS population: coronary heart disease (8.3 vs. $2.7 \%$ ), stroke (2.1 vs. $0 \%$ ), heart failure (3.1 vs. $0.5 \%$ ), and depression (15.6 vs. 9.1\%).

\subsection{Prior Medications}

All patients in the AS and PsA groups had received prior treatment with a pharmacological compound; the proportion of patients treated with NSAIDs and DMARDs varied between the two groups (Table 3). Previous DMARD exposure was much higher in the PsA group (72.7\%) compared with the AS group (37.4\%), as expected according to treatment recommendations, whereas previous use of NSAIDs was twice as high in AS patients (59.9\%) compared with PsA patients (24.9\%). Among the listed DMARDs, methotrexate $(21.4 \%)$ and sulfasalazine $(26.7 \%)$ in AS while methotrexate $(56.9 \%)$ and leflunomide $(28.6 \%)$ in PsA patients seem to be most common (Table 3). The most frequent prior treatment among both AS and PsA patients included biologics (TNF inhibitor, $51.9 \%$, ustekinumab, $14.5 \%$ ). A total of $64.2 \%$ of AS patients and $67.5 \%$ PsA patients had previously received biologic treatments, but a majority of these patients were nonresponders (AS, 72.2\%; PsA, 76.1\%). Biologic-experienced AS patients had received adalimumab and etanercept most frequently (43.3\% and $39.0 \%$, respectively) among the listed biologic DMARDs, followed by golimumab, infliximab and certolizumab pegol. Biosimilars of infliximab and etanercept were in the low single digit percentage range. A similar trend was observed in biologic-experienced PsA patients; among the listed biologics, adalimumab was the most common (42.6\%), followed by etanercept (31.4\%), ustekinumab, golimumab, infliximab, and certolizumab pegol. Biosimilars were received by $1.3 \%$ of patients with PsA (Table 3). About one-third of all patients $(34.8 \%$ of AS and $29.8 \%$ PsA) included in this realworld study received secukinumab as a first-line biologic agent within 15 months after its approval (data cut-off, 01.02.2017).

\section{DISCUSSION}

While secukinumab trial programs have demonstrated the clinical efficacy and tolerability of secukinumab in patients with PsA [14, 25] and AS [13], there remains a clear need for verifying effectiveness, sustainability, and safety data in realworld settings. In the current study, we collected data that describe real-world experiences of patients with high disease activity of AS or PsA in Germany who are suitable for treatment with secukinumab $[26,27]$.

The baseline characteristics (gender, weight, BMI, smoker status) of the AQUILA NIS population were comparable to AS and PsA populations of previous secukinumab trials except the

Table 3. Prior therapies in patients with AS and PsA.

\begin{tabular}{|c|c|c|c|c|}
\hline Prior therapies, n (\%) & $\begin{array}{c}A S \\
(N=187)\end{array}$ & $\begin{array}{c}\text { PsA } \\
(N=385)\end{array}$ & $\begin{array}{c}\text { P-value } \\
\text { (Chi-square test) }\end{array}$ & $\begin{array}{c}\text { Total } \\
(N=572)\end{array}$ \\
\hline NSAIDs & $112(59.9)$ & $96(24.9)$ & $<.0001$ & $208(36.4)$ \\
\hline Other analgesics & $32(17.1)$ & $31(8.1)$ & 0.0012 & $63(11.0)$ \\
\hline DMARDs & $70(37.4)$ & $280(72.7)$ & - & $350(61.2)$ \\
\hline Methotrexate * & $40(21.4)$ & $219(56.9)$ & $<.0001$ & $259(45.3)$ \\
\hline Azathioprin * & $1(0.5)$ & $4(1.0)$ & 0.5434 & $5(0.9)$ \\
\hline Sulfasalazin * & $50(26.7)$ & $66(17.1)$ & 0.0074 & $116(20.3)$ \\
\hline Leflunomid * & $11(5.9)$ & $110(28.6)$ & $<.0001$ & $121(21.2)$ \\
\hline Cyclosporine * & 0 & $42(10.9)$ & $<.0001$ & $42(7.3)$ \\
\hline Chloroquin/hydrochloroquin * & $2(1.1)$ & $7(1.8)$ & 0.4997 & $9(1.6)$ \\
\hline Gold compound * & $2(1.1)$ & $4(1.0)$ & 0.9732 & $6(1.0)$ \\
\hline Secukinumab $^{\# *}$ & $37(19.8)$ & $91(23.6)$ & NA & $128(22.4)$ \\
\hline Other biologics & $120(64.2)$ & $260(67.5)$ & - & $380(66.4)$ \\
\hline Adalimumab * & $81(43.3)$ & $164(42.6)$ & 0.8707 & $245(42.8)$ \\
\hline Etanercept * & $73(39.0)$ & $121(31.4)$ & 0.0714 & $194(33.9)$ \\
\hline Infliximab * & $41(21.9)$ & $42(10.9)$ & 0.0004 & $83(14.5)$ \\
\hline Certolizumab pegol * & $38(20.3)$ & $40(10.4)$ & 0.0012 & $78(13.6)$ \\
\hline Golimumab * & $54(28.9)$ & $65(16.9)$ & 0.0009 & $119(20.8)$ \\
\hline Ustekinumab * & $1(0.5)$ & $82(21.3)$ & $<.0001$ & $83(14.5)$ \\
\hline Biosimilars & $2(1.1)$ & $5(1.3)$ & - & $7(1.2)$ \\
\hline Infliximab & $1(0.5)$ & $5(1.3)$ & 0.7421 & $6(1.0)$ \\
\hline Etanercept & $1(0.5)$ & 0 & 0.1510 & $1(0.2)$ \\
\hline Others & $24(12.8)$ & $73(19.0)$ & - & $97(17.0)$ \\
\hline Apremilast & 0 & $24(6.2)$ & 0.0005 & $24(4.2)$ \\
\hline
\end{tabular}

"Start of secukinumab therapy prior to BSL.

*Many patients were exposed to more than one DMARD/biologic.

AS, ankylosing spondylitis; DMARDs, Disease-Modifying Anti-Rheumatic Drugs; NA, Not Applicable/Not Available; NSAIDs, Non-Steroidal Anti-Inflammatory Drugs; PsA, psoriatic arthritis. 
age which was slightly higher (RCTs 40.1- 49.6 years; AQUILA 46.6-53.0 years) [13, 14, 25]. AS and PsA patients had active disease at baseline in all parameters collected to confirm disease activity. Disease activity in the current NIS was almost as high as activity reported in randomized clinical studies, e.g. BASDAI mean of 6.1-6.8 (AQUILA 5.5) and PASI mean score of 10.7-15.6 (AQUILA 8.8) [13, 14], despite the fact that the majority (over 65\%) of the patients had received prior biologic therapies immediately before the start of secukinumab therapy (RCTs 26-39\%). This high disease activity also indicates that a significant proportion of patients with AS and PsA experienced an inadequate response or intolerance to prior biologic treatment.

In this real-world setting, about one-third of AS and PsA patients received secukinumab as a first-line biologic agent within 15 months after its approval, indicating high usage of IL-17A inhibitors as first-line biologic therapy (cut-off date for data analysis: 01.02.2017). Based on expert opinion in the recently updated guidelines from ASAS-European League Against Rheumatism (EULAR) [28], the initiation of biologics is recommended in patients with axial $\mathrm{SpA}$ if an inadequate response or intolerance was reported to previous conventional treatment options. According to EULAR 2015 recommendations for the management of PsA, it is current practice to initiate biologic therapy with a TNF inhibitor, but first-line treatment with secukinumab can be initiated in selected patients with PsA (those with peripheral arthritis and with an inadequate response to at least one conventional synthetic DMARD, in whom TNFs are not appropriate [9]. At baseline, only a small proportion of patients with AS and PsA had been exposed to biosimilars, which might be due to the fact that many biosimilars have only recently gained market approval.

There are essential differences in the frequency of comorbidities among PsA and AS patients. Coronary heart disease, stroke, and heart failure were all more common in PsA patients, and uveitis was reported more frequently in AS patients entering the AQUILA NIS, reflecting the real-world study design of this trial. Previous studies have shown similar results, with cardiovascular disease reported as the most significant comorbidity in PsA patients [29, 30]. Likewise, uveitis, a common comorbidity associated with AS, was reported in $19.6 \%$ of all patients of the COMOSPA Study [31]. Explanation for lower uveitis rate observed in the medical history of patients of the AQUILA NIS may be the lack of specific questions related to uveitis other than in the medical history, the lack of ophthalmologist assessments and the relatively high percentage of biologic-pretreated patients that might lead to lower reported uveitis rates. Although two secukinumab studies on uveitis [32,33] have been conducted, there seem to be a lack of clarity about the role of IL-17 inhibition in uveitis, thus fewer patients with uveitis history were included. Depression and psoriasis are known common comorbidities reported in AS [34, 35], and depression is a known comorbidity in PsA patients [36, 37]. Psoriasis and depression were the most frequently reported comorbidities at baseline among all patients entering the AQUILA NIS.

Our results reflect the reality that many patients with PsA or AS are not diagnosed in a timely manner. The delay or failure in the diagnosis of PsA among psoriasis patients has been reported in previous studies [38, 39]. In the present study, approximately $1 / 4^{\text {th }}$ of AS and PsA patients lacked a confirmed diagnosis for 10 years or more after symptom onset; only $40.4 \%$ had a confirmed diagnosis within 2 years.

The main limitations of this study include patient selection criteria (patients need to be available for the whole duration of the observation period of 12 months), missing values (performed clinical assessments differ between sites), lower frequency of assessments as dictated by clinical routine (a 3 month instead of 4 week period at RCTs), and furthermore, no evaluation of ASAS/ACR response criteria (commonly used in RCTs) due to the fact that not all parameters of which ASAS/ACR consists of are assessed (NIS, clinical practice).

Besides representing the similarities and differences between data from randomized clinical trials and real-world settings, the high prevalence of depression in both entities as shown in this baseline data may argue to intensify assessment and anti-depressive treatment strategies in the concept for positive patient outcome.

\section{CONCLUSION}

The results from this non-interventional study may be useful to link the efficacy and sustainability of therapeutic effect of secukinumab on disease activity scores as well as on patient-relevant parameters as assessed in day-to-day practice.

\section{LIST OF ABBREVIATIONS}

$\begin{array}{ll}\text { NIS } & =\text { Non Interventional Study } \\ \text { AS } & =\text { Ankylosing Spondylitis } \\ \text { QoL } & =\text { Quality of Life } \\ \text { NSAIDs } & =\text { Non Steroidal Anti Inflammatory Drugs } \\ \text { DMARDS } & =\text { Disease Modifying Antirheumatic Drugs } \\ \text { RCTs } & =\text { Randomized Clinical Trials } \\ \text { CRP } & =\text { C-Reactive Protein } \\ \text { SD } & =\text { Standard Deviation } \\ \text { BMI } & =\text { Bone Mass Index } \\ \text { HLA } & =\text { Human Leukocye Antigen }\end{array}$

\section{AUTHORS' CONTRIBUTIONS}

All authors had access to the data, contributed to its interpretation and collaborated in the development of the manuscript. The initial draft of the manuscript was written by a medical writer employed by the study sponsor. All authors critically reviewed and provided feedback on subsequent versions. All authors made the decision to submit the manuscript for publication and vouch for the accuracy and completeness of the data and fidelity of this report to the study protocol.

\section{ETHICS APPROVAL AND CONSENT TO PARTI- CIPATE}

The ethics committee (University of Würzburg, Germany) advice was obtained and recommendations implemented. 


\section{HUMAN AND ANIMAL RIGHTS}

No Animals were used in this research. All human research procedures followed were in accordance with the ethical standards of the committee responsible for human experimentation (institutional and national), and with the Helsinki Declaration of 1975, as revised in 2013.

\section{CONSENT FOR PUBLICATION}

All patients gave informed consent.

\section{AVAILABILITY OF DATA AND MATERIALS}

Novartis is committed to sharing with qualified external researchers, access to patient-level data and supporting clinical documents from eligible studies. These requests are reviewed and approved by an independent review panel on the basis of scientific merit. All data provided are anonymized to respect the privacy of patients who have participated in the trial in line with applicable laws and regulations. The trial data availability is according to the criteria and process described on www.clinicalstudydatarequest.com.

\section{FUNDING}

This research was funded by Novartis Pharma GmbH, Germany.

\section{CONFLICT OF INTEREST}

UK has received grant, research support and consultancy fees from AbbVie, Grünenthal, Jansens, MSD, Novartis, Pfizer, Roche, and UCB; CL, MMP, and CM are employees of Novartis Pharma GmbH, Germany; HPT, received personal fees from Abbvie, Chugai, Janssen Cilag, Lilly, Novartis, Roche, Sandoz Hexal, Sanofi Aventis.

\section{ACKNOWLEDGEMENTS}

The study was sponsored by Novartis Pharma GmbH, Germany. The authors thank the patients who participated in this study. Manuscript writing support was provided by Santoshkumar Tota and Divya Chandrasekhar, Novartis Healthcare Pvt Ltd, Hyderabad, India.

\section{REFERENCES}

[1] Braun J, Sieper J. Ankylosing spondylitis. Lancet 2007; 369(9570): 1379-90.

[http://dx.doi.org/10.1016/S0140-6736(07)60635-7] [PMID: 174488 25]

[2] Gladman DD, Antoni C, Mease P, Clegg DO, Nash P. Psoriatic arthritis: epidemiology, clinical features, course, and outcome. Ann Rheum Dis 2005; 64(Suppl. 2): ii14-7.

[http://dx.doi.org/10.1136/ard.2004.032482] [PMID: 15708927]

[3] Kiltz U, van der Heijde D. Health-related quality of life in patients with rheumatoid arthritis and in patients with ankylosing spondylitis. Clin Exp Rheumatol 2009; 27(4)(Suppl. 55): S108-11. [PMID: 19822055]

[4] Tam LS, Gu J, Yu D. Pathogenesis of ankylosing spondylitis. Nat Rev Rheumatol 2010; 6(7): 399-405.

[http://dx.doi.org/10.1038/nrrheum.2010.79] [PMID: 20517295]

[5] Boonen A, van der Linden SM. The burden of ankylosing spondylitis. J Rheumatol Suppl 2006; 78: 4-11. [PMID: 17042055]

[6] Dean LE, Jones GT, MacDonald AG, Downham C, Sturrock RD, Macfarlane GJ. Global prevalence of ankylosing spondylitis. Rheumatology (Oxford) 2014; 53(4): 650-7. [http://dx.doi.org/10.1093/rheumatology/ket387] [PMID: 24324212]

[7] Braun J, Sieper J. Spondylarthritides. Z Rheumatol 2006; 65(7): 613-31.

[http://dx.doi.org/10.1007/s00393-006-0116-6] [PMID: 17072572]

[8] Braun J, van den Berg R, Baraliakos X, et al. 2010 update of the ASAS/EULAR recommendations for the management of ankylosing spondylitis. Ann Rheum Dis 2011; 70(6): 896-904.

[http://dx.doi.org/10.1136/ard.2011.151027] [PMID: 21540199]

[9] Gossec L, Smolen JS, Ramiro S, et al. European League Against Rheumatism (EULAR) recommendations for the management of psoriatic arthritis with pharmacological therapies: 2015 update. Ann Rheum Dis 2016; 75(3): 499-510.

[http://dx.doi.org/10.1136/annrheumdis-2015-208337] [PMID: 266442 32]

[10] Carneiro S, Azevedo VF, Bonfiglioli R, et al. Recommendations for the management and treatment of psoriatic arthritis. Rev Bras Reumatol 2013; 53(3): 227-41.

[http://dx.doi.org/10.1590/S0482-50042013000300002] [PMID: 24051 907]

[11] Golmia RP, Martins AH, Scheinberg M. When anti-TNF fails, antiIL12-23 is an alternate option in psoriasis and psoriatic arthritis. Rev Bras Reumatol 2014; 54(3): 247-9.

[http://dx.doi.org/10.1016/j.rbr.2013.10.002] [PMID: 25054605]

[12] Duarte JH. Spondyloarthropathies: IL-17A blockade ameliorates ankylosing spondylitis. Nat Rev Rheumatol 2016; 12(2): 72.

[http://dx.doi.org/10.1038/nrrheum.2016.7] [PMID: 26794859]

[13] Baeten D, Baraliakos X, Braun J, et al. Anti-interleukin-17A monoclonal antibody secukinumab in treatment of ankylosing spondylitis: A randomised, double-blind, placebo-controlled trial. Lancet 2013; 382(9906): 1705-13.

[http://dx.doi.org/10.1016/S0140-6736(13)61134-4] [PMID: 240352 50]

[14] Mease PJ, McInnes IB, Kirkham B, et al. Secukinumab inhibition of interleukin-17A in patients with psoriatic arthritis. N Engl J Med 2015; 373(14): 1329-39.

[http://dx.doi.org/10.1056/NEJMoa1412679] [PMID: 26422723]

[15] Langley RG, Elewski BE, Lebwohl M, et al. Secukinumab in plaque psoriasis-results of two phase 3 trials. N Engl J Med 2014; 371(4): 326-38.

[http://dx.doi.org/10.1056/NEJMoa1314258] [PMID: 25007392]

[16] Commission implementing decision: Amending the marketing authorisation granted by Decision C(2015)203(final) for "Cosentyx secukinumab", a medicinal product for human use. 2015. Available from:

http://ec.europa.eu/health/documents/communityregister/2015/201511 19133485/dec_133485_en.pdf

[17] SUMMARY OF PRODUCT CHARACTERISTICS. Available from: http://www.ema.europa.eu/docs/en_GB/document_library/EPAR_Prod uct Information/human/003729/WC500183129.pdf

[18] Freedman JD, Gottlieb AB, Lizzul PF. Physician performance measurement: Tiered networks and dermatology (an opportunity and a challenge). J Am Acad Dermatol 2011; 64(6): 1164-9.

[http://dx.doi.org/10.1016/j.jaad.2010.07.004] [PMID: 21571173]

[19] Garrett S, Jenkinson T, Kennedy LG, Whitelock H, Gaisford P, Calin A. A new approach to defining disease status in ankylosing spondylitis: The Bath Ankylosing Spondylitis Disease Activity Index. J Rheumatol 1994; 21(12): 2286-91. [PMID: 7699630]

[20] Weisman S, Pollack CR, Gottschalk RW. Psoriasis disease severity measures: Comparing efficacy of treatments for severe psoriasis. J Dermatolog Treat 2003; 14(3): 158-65.

[http://dx.doi.org/10.1080/09546630310013360] [PMID: 14522626]

[21] Felson DT, Anderson JJ, Boers M, et al. American college of rheumatology. preliminary definition of improvement in rheumatoid arthritis. Arthritis Rheum 1995; 38(6): 727-35.

[http://dx.doi.org/10.1002/art.1780380602] [PMID: 7779114]

[22] Kiltz U, van der Heijde D, Boonen A, et al. Development of a health index in patients with ankylosing spondylitis (ASAS HI): Final result of a global initiative based on the ICF guided by ASAS. Ann Rheum Dis 2015 ; 74(5): 830-5.

[http://dx.doi.org/10.1136/annrheumdis-2013-203967] [PMID: 24399 232]

[23] Gossec L, de Wit M, Kiltz U, et al. A patient-derived and patientreported outcome measure for assessing psoriatic arthritis: Elaboration and preliminary validation of the Psoriatic Arthritis Impact of Disease (PsAID) questionnaire, a 13-country EULAR initiative. Ann Rheum Dis 2014; 73(6): 1012-9. 
[http://dx.doi.org/10.1136/annrheumdis-2014-205207] [PMID: 2479 0067]

[24] Beck AT, Steer RA, Carbin MG. Psychometric properties of the Beck Depression Inventory: Twenty-five years of evaluation. Clin Psychol Rev 1988; 8: 77-100.

[http://dx.doi.org/10.1016/0272-7358(88)90050-5]

[25] McInnes IB, Mease PJ, Kirkham B, et al. Secukinumab, a human antiinterleukin-17A monoclonal antibody, in patients with psoriatic arthritis (FUTURE 2): A randomised, double-blind, placebocontrolled, phase 3 trial. Lancet 2015; 386(9999): 1137-46. [http://dx.doi.org/10.1016/S0140-6736(15)61134-5] [PMID: 26135 703]

[26] NIH. Overweight and Obesity Statistics. 2012. Available from: https://www.niddk.nih.gov/health-information/health-statistics/overwe ight-obesity

[27] Summary of product characteristics: Cosentyx https://ec.europa.eu /health/documents/community-register/2015/20150115130444/anx 130444_en.pdf

[28] van der Heijde D, Ramiro S, Landewé R, et al. 2016 update of the ASAS-EULAR management recommendations for axial spondyloarthritis. Ann Rheum Dis 2017; 76(6): 978-91. [http://dx.doi.org/10.1136/annrheumdis-2016-210770] [PMID: 2808 7505]

[29] Haddad A, Zisman D. Comorbidities in patients with psoriatic arthritis. Rambam Maimonides Med J 2017; 8(1): 8.

[http://dx.doi.org/10.5041/RMMJ.10279] [PMID: 28178440]

[30] Ogdie A, Yu Y, Haynes K, et al. Risk of major cardiovascular events in patients with psoriatic arthritis, psoriasis and rheumatoid arthritis: A population-based cohort study. Ann Rheum Dis 2015; 74(2): 326-32. [http://dx.doi.org/10.1136/annrheumdis-2014-205675] [PMID: 2535 1522]

[31] Bautista-Molano W, Landewé R, Burgos-Vargas R, et al. Prevalence of comorbidities and risk factors for comorbidities in patients with spondyloarthritis in latin america: A comparative study with the general population and data from the ASAS-COMOSPA study. J Rheumatol 2018; 45(2): 206-12.

[http://dx.doi.org/10.3899/jrheum.170520] [PMID: 29247152]

[32] Letko E, Yeh S, Foster CS, Pleyer U, Brigell M, Grosskreutz CL.
Efficacy and safety of intravenous secukinumab in noninfectious uveitis requiring steroid-sparing immunosuppressive therapy. Ophthalmology 2015; 122(5): 939-48.

[http://dx.doi.org/10.1016/j.ophtha.2014.12.033] [PMID: 25638011]

[33] Hueber W, Patel DD, Dryja T, et al. Effects of AIN457, a fully human antibody to interleukin-17A, on psoriasis, rheumatoid arthritis, and uveitis. Sci Transl Med 2010; 2(52)52ra72

[http://dx.doi.org/10.1126/scitranslmed.3001107] [PMID: 20926833]

[34] Martindale J, Smith J, Sutton CJ, Grennan D, Goodacre L, Goodacre JA. Disease and psychological status in ankylosing spondylitis. Rheumatology (Oxford) 2006; 45(10): 1288-93.

[http://dx.doi.org/10.1093/rheumatology/kel115] [PMID: 16595514]

[35] Rudwaleit M, van der Heijde D, Landewé R, et al. The assessment of spondyloArthritis international society classification criteria for peripheral spondyloarthritis and for spondyloarthritis in general. Ann Rheum Dis 2011; 70(1): 25-31.

[http://dx.doi.org/10.1136/ard.2010.133645] [PMID: 21109520]

[36] Krueger G, Koo J, Lebwohl M, Menter A, Stern RS, Rolstad T. The impact of psoriasis on quality of life: Results of a 1998 national psoriasis foundation patient-membership survey. Arch Dermatol 2001; 137(3): 280-4.

[PMID: 11255325]

[37] Roubille C, Richer V, Starnino T, et al. Evidence-based recommendations for the management of comorbidities in rheumatoid arthritis, psoriasis, and psoriatic arthritis: Expert opinion of the canadian dermatology-rheumatology comorbidity initiative. J Rheumatol 2015; 42(10): 1767-80.

[http://dx.doi.org/10.3899/jrheum.141112] [PMID: 26178281]

[38] Cobo-Ibáñez T, Villaverde V, Seoane-Mato D, et al. Multidisciplinary dermatology-rheumatology management for patients with moderateto-severe psoriasis and psoriatic arthritis: A systematic review. Rheumatol Int 2016; 36(2): 221-9.

[http://dx.doi.org/10.1007/s00296-015-3377-z] [PMID: 26438388]

[39] Villani AP, Rouzaud M, Sevrain M, et al. Prevalence of undiagnosed psoriatic arthritis among psoriasis patients: Systematic review and meta-analysis. J Am Acad Dermatol 2015; 73(2): 242-8. [http://dx.doi.org/10.1016/j.jaad.2015.05.001] [PMID: 26054432]

\section{(C) 2019 Kiltz et al.}

This is an open access article distributed under the terms of the Creative Commons Attribution 4.0 International Public License (CC-BY 4.0), a copy of which is available at: https://creativecommons.org/licenses/by/4.0/legalcode. This license permits unrestricted use, distribution, and reproduction in any medium, provided the original author and source are credited. 